\title{
Review Article \\ Roles of Renal Proximal Tubule Transport in Acid/Base Balance and Blood Pressure Regulation
}

\author{
Motonobu Nakamura, Ayumi Shirai, Osamu Yamazaki, Nobuhiko Satoh, Masashi Suzuki, \\ Shoko Horita, Hideomi Yamada, and George Seki \\ Department of Internal Medicine, Faculty of Medicine, The University of Tokyo, 7-3-1 Hongo, Bunkyo-ku, Tokyo 113-0033, Japan \\ Correspondence should be addressed to George Seki; georgeseki-tky@umin.ac.jp
}

Received 5 May 2014; Accepted 16 May 2014; Published 28 May 2014

Academic Editor: Yoshinori Marunaka

Copyright (c) 2014 Motonobu Nakamura et al. This is an open access article distributed under the Creative Commons Attribution License, which permits unrestricted use, distribution, and reproduction in any medium, provided the original work is properly cited.

\begin{abstract}
Sodium-coupled bicarbonate absorption from renal proximal tubules (PTs) plays a pivotal role in the maintenance of systemic acid/base balance. Indeed, mutations in the $\mathrm{Na}^{+}-\mathrm{HCO}_{3}{ }^{-}$cotransporter $\mathrm{NBCel}$, which mediates a majority of bicarbonate exit from PTs, cause severe proximal renal tubular acidosis associated with ocular and other extrarenal abnormalities. Sodium transport in PTs also plays an important role in the regulation of blood pressure. For example, PT transport stimulation by insulin may be involved in the pathogenesis of hypertension associated with insulin resistance. Type 1 angiotensin (Ang) II receptors in PT are critical for blood pressure homeostasis. Paradoxically, the effects of Ang II on PT transport are known to be biphasic. Unlike in other species, however, Ang II is recently shown to dose-dependently stimulate human PT transport via nitric oxide/cGMP/ERK pathway, which may represent a novel therapeutic target in human hypertension. In this paper, we will review the physiological and pathophysiological roles of PT transport.
\end{abstract}

\section{Introduction}

Renal proximal tubules (PTs) reabsorb approximately $80 \%$ of the filtered bicarbonate from glomerulus, thereby playing a pivotal role in the maintenance of systemic acid-base balance [1]. This process is mostly dependent on $\mathrm{Na}^{+}$, which is composed of the luminal $\mathrm{Na}^{+} / \mathrm{H}^{+}$exchanger and the basolateral $\mathrm{Na}^{+}-\mathrm{HCO}_{3}{ }^{-}$cotransporter [1]. Although distal nephron segments are also involved in the systemic acid/base regulation, acid-base transporters in these segments often cannot completely compensate for defects in bicarbonate absorption from PTs. Indeed, mutations in the $\mathrm{Na}^{+}-\mathrm{HCO}_{3}{ }^{-}$ cotransporter NBCel, which mediates a majority of bicarbonate exit from the basolateral membrane of PTs, are known to cause a severe type of proximal renal tubular acidosis associated with ocular and other extrarenal manifestations [2].

On the other hand, PTs reabsorb approximately $65 \%$ of the filtered $\mathrm{NaCl}$, thereby also contributing to the regulation of plasma volume and blood pressure. For example, hypertension is frequently associated with metabolic syndrome, and insulin-mediated stimulation of PT transport may play a role in this association $[3,4]$. In addition, angiotensin (Ang) II is pivotal in the regulation of blood pressure, and stimulation of PT transport may play a critical role in Ang II-mediated hypertension $[5,6]$. In this review, we will focus on the roles of PT transport in the maintenance of acid-base homeostasis as well as the regulation of blood pressure.

\section{Roles of PT Transport in Acid/Base Balance}

In PTs, the luminal $\mathrm{Na}^{+} / \mathrm{H}^{+}$exchanger type 3 (NHE3) together with the basolateral $\mathrm{Na}^{+}-\mathrm{HCO}_{3}{ }^{-}$cotransporter NBCel is thought to mediate a majority of sodium-coupled bicarbonate absorption from this segment $[1,7]$. Although the basolateral membrane of PTs contains $\mathrm{Na}^{+}$-dependent and $\mathrm{Na}^{+}$-independent $\mathrm{Cl}^{-} / \mathrm{HCO}_{3}{ }^{-}$exchangers [7], these transporters cannot effectively compensate for the loss of $\mathrm{NBCel}$ function. By contrast, the loss of NHE3 function may be at least partially compensated by the other luminal transporters such as NHE8 [8]. 
In 1983 Boron and Boulpaep identified the functional existence of electrogenic $\mathrm{Na}^{+}$-coupled $\mathrm{HCO}_{3}{ }^{-}$transport activity in the basolateral membrane of isolated salamander PTs [9]. Subsequently, Kondo and Frömter revealed that this electrogenic $\mathrm{Na}^{+}-\mathrm{HCO}_{3}{ }^{-}$cotransport activity is robust in S1 and S2 segments but almost absent in S3 segment of isolated rabbit PTs [10]. Yoshitomi and colleagues initially reported that the $\mathrm{Na}^{+}-\mathrm{HCO}_{3}{ }^{-}$cotransporter in rat PTs in vivo functions with $1 \mathrm{Na}^{+}$to $3 \mathrm{HCO}_{3}{ }^{-}$stoichiometry [11]. On the other hand, Seki and colleagues revealed that the $\mathrm{Na}^{+}-$ $\mathrm{HCO}_{3}{ }^{-}$cotransporter in isolated rabbit PTs functions with $1 \mathrm{Na}^{+}$to $2 \mathrm{HCO}_{3}{ }^{-}$stoichiometry [12]. Later, Müller-Berger and colleagues found that the $\mathrm{Na}^{+}-\mathrm{HCO}_{3}{ }^{-}$cotransporter in isolated rabbit PTs can change its transport stoichiometry depending on the incubation conditions [13]. Interestingly, NBCel expressed in Xenopus oocytes can also change its transport stoichiometry depending on changes in cytosolic $\mathrm{Ca}^{2+}$ concentrations [14]. Consistent with these data, Gross and colleagues reported that stoichiometry of NBCel is celltype specific [15].

In 1997 Romero and colleagues succeeded in the first molecular cloning of NBCel from salamander kidney [16]. Among the three major variants, NBCelA is transcribed from the alternative promoter in exon 1 and abundantly expressed in the basolateral membrane of PTs, representing the major bicarbonate exit pathway in this nephron segment [1]. Another variant NBCelB is transcribed from the dominant promoter in exon 1 and differs from NBCelA only at the N-terminus [17]. NBCe1B is first cloned from pancreas but is now known to be expressed in a variety of tissues such as intestinal tracts, ocular tissues, and brain [18-20]. On the other hand, NBCelC is predominantly expressed in brain and differs from NBCelB only at the C-terminus [21]. Consistent with the indispensable role of NBCel in acid/base homeostasis, Igarashi and colleagues found that inactivating mutations in NBCel cause a severe type of proximal renal tubular acidosis (pRTA) associated with ocular abnormalities [2]. Until now 12 different homozygous mutations have been found in pRTA patients [22]. These patients invariably presented with ocular abnormalities such as band keratopathy, cataract, and glaucoma, suggesting that NBCe1 function is essential for the maintenance of homeostasis in ocular tissues. Indeed, NBCel is found to be abundantly expressed in several human ocular tissues such as corneal endothelium, lens epithelium, and trabecular meshwork cells [20].

NBCel in brain may also play several physiological roles [23]. Indeed, Suzuki and colleagues revealed that defective membrane expression of NBCelB may cause migraine with or without hemiplegia [24]. NBCe1B activity in astrocytes may be indispensable for the regulation of synaptic $\mathrm{pH}$ and neuron excitability.

Two types of NBCel-deficient mice, NBCel-KO mice [25] and W516X-knockin mice [26], present with very severe acidemia due to pRTA and die within 30 days. Functional analysis using isolated PTs from W516X-knockin mice confirmed that the normal NBCel activity is essential for bicarbonate absorption from this nephron segment [26].
Alkali therapy significantly prolonged the survival of W516Xknockin mice. Detailed analysis of ocular tissues in these mice revealed that NBCel plays a critical role in the maintenance of corneal transparency also in mice [26].

Unlike NBCel-deficient mice, NHE3-KO mice present with only mild acidemia [27]. Although NHE8 seems to partially compensate for the loss of NHE3 function, NHE3/NHE3-double KO mice also present with relatively mild acidemia [8]. So far, mutations in NHE3 or NHE8 have not been found in human pRTA patients.

\section{Roles of Hyperinsulinemia in Hypertension Associated with Metabolic Syndrome}

Certain risk factors such as abdominal adiposity, glucose intolerance, dyslipidemia, and hypertension tend to cluster within individuals. Insulin resistance with obesity is thought to be a key factor for this association, which is now termed as metabolic syndrome [28]. Several different mechanisms such as activation of renin-angiotensin-aldosterone system (RAAS), enhancement of sympathetic nervous system, or hyperinsulinemia may be involved in the occurrence of hypertension associated with insulin resistance [29, 30]. Among these factors, hyperinsulinemia-induced hypertension seems to be an attractive hypothesis in view of the antinatriuretic action of insulin $[3,4]$. Indeed, insulin is known to stimulate sodium absorption from several nephron segments. For example, insulin may stimulate sodium absorption from distal convoluted tubules by phosphorylating the $\mathrm{Na}^{+}$$\mathrm{Cl}^{-}$cotransporter NCC through the with-no-lysine kinase 4 (WNK4)/STE20/SPS1-related proline-alanine-rich kinase (SPAK) pathway [31]. In cortical collecting duct (CCD) cells insulin is thought to stimulate sodium absorption by activating the activity of epithelial $\mathrm{Na}^{+}$channel ENaC [32$34]$, though a recent study failed to confirm the stimulatory effect of insulin on the $\mathrm{ENaC}$ activity in isolated mammalian CCD [35]. In PTs, insulin enhances sodium absorption by stimulating the luminal NHE3, the basolateral $\mathrm{Na}^{+} / \mathrm{K}^{+}$ATPase, and the basolateral NBCe1 [36-39].

Insulin can relax vascular tones through the phosphatidylinositol 3 kinase (PI3K)/Akt-dependent nitric oxide (NO) production, and simple hyperinsulinemia may not necessarily induce hypertension [40]. Notably, however, the vasodilator action of insulin is reported to be attenuated in insulin resistance [41, 42]. Therefore, hyperinsulinemia can be an important factor in hypertension associated with metabolic syndrome, if the stimulatory effects of insulin on renal sodium absorption are preserved even in the systemic insulin resistance.

In support of this hypothesis, recent studies have clarified that defects in insulin signaling at the level of insulin receptor substrate (IRS) proteins are frequently associated with human insulin resistant states, resulting in the occurrence of cell-type specific insulin resistance $[43,44]$. The two major substrates IRS1 and IRS2 may mediate distinct pathways in insulin signaling, and they are not functionally interchangeable in many insulin-sensitive tissues [43-45]. Importantly, in adipocytes of human subjects with noninsulin-dependent 
diabetes mellitus the expression of IRS1 protein is found to be markedly reduced, accompanied with the severe reduction of insulin-mediated glucose uptake [46]. By contrast, the reduction of IRS2 expression seems to be a key factor in several forms of insulin resistance in liver [47].

To clarify the relative importance of IRS1 and IRS2 in the stimulatory effect of insulin on PT transport, Zheng and colleagues compared the effects of insulin on sodiumcoupled bicarbonate absorption in isolated PTs from IRS1$\mathrm{KO}$ and IRS2-KO mice. They found that the PI3 K-dependent stimulatory effect of insulin on PT transport was preserved in IRS1-KO mice but markedly attenuated in IRS2-KO mice. Furthermore, insulin-induced Akt phosphorylation was also preserved in IRS1-KO mice but not in IRS-2 KO mice [48]. These results indicate that IRS2 is the main substrate that mediates the stimulatory effects of insulin on PT transport. Importantly, insulin can induce antinatriuresis even in insulin resistant rats and humans [49, 50]. Moreover, PT sodium transport seems to be enhanced in insulin resistant humans [51, 52], suggesting that the stimulatory effect of insulin on PT transport may be preserved in common forms of insulin resistance. Consistent with this view, a recent study showed that the expression of IRS2 as well as insulin-mediated Akt phosphorylation in renal tubules is preserved in Zucker fatty rats that show marked insulin resistance due to defective leptin signaling [53]. In liver, hyperinsulinemia is known to suppress the expression of IRS2, thereby attenuating the insulin signaling in liver $[47,54]$. Future studies are required to determine whether the IRS2-dependent stimulatory insulin signaling in PTs is preserved in common forms of insulin resistance.

Interestingly, the IRS1-dependent insulin signaling in glomeruli seems to be attenuated in insulin resistance [53]. Because insulin signaling may be required not only for the nitric oxide (NO) production by glomerular endothelium but also for the preservation of normal podocyte functions $[53,55]$, insulin resistance in glomeruli may promote the occurrence and progression of diabetic nephropathy. In fact, the treatment with insulin sensitizers thiazolidinediones (TZDs) can protect podocyte from injury independently of glycemic control [56]. However, TZDs, especially when used with insulin, may induce edema formation as a side effect, probably by stimulating sodium absorption from PT and/or distal tubules $[57,58]$. Unfortunately, this side effect may offset the beneficial effects of TZDs on the insulin signaling in glomeruli.

\section{Effects of Ang II on PT Transport}

There are two major Ang II receptors (AT), $\mathrm{AT}_{1}$ and $\mathrm{AT}_{2}$. $\mathrm{AT}_{1}$ receptors are further subdivided into $\mathrm{AT}_{1 \mathrm{~A}}$ and $\mathrm{AT}_{1 \mathrm{~B}}$ in rodents [59]. While $\mathrm{AT}_{1}$ may be the main receptors that mediate the effects of Ang II on blood pressure, $\mathrm{AT}_{2}$ may be also partially involved in blood pressure regulation [60]. Ang II can regulate blood pressure via $\mathrm{AT}_{1}$ receptors in both renal and extrarenal tissues. To clarify the relative importance of these receptors in blood pressure homeostasis, Coffman and colleagues performed kidney cross-transplantation between wild-type and $\mathrm{AT}_{1 \mathrm{~A}}-\mathrm{KO}$ mice $[5,6]$. They found that renal and extrarenal $\mathrm{AT}_{1 \mathrm{~A}}$ receptors almost equally contribute to the maintenance of baseline blood pressure. However, renal $\mathrm{AT}_{1 \mathrm{~A}}$ receptors are indispensable for the occurrence of Ang II-induced hypertension and cardiac hypertrophy. They further showed that specific deletion of $\mathrm{AT}_{1 \mathrm{~A}}$ receptors from PTs alone is sufficient to lower blood pressure and provides substantial protection against Ang II-induced hypertension [61]. These results indicate that the stimulatory effect of Ang II on PT sodium transport is quite important in blood pressure regulation.

Paradoxically, however, the effects of Ang II on PT transport are biphasic: transport is stimulated by picomolar to nanomolar concentrations of Ang II, while it is inhibited by nanomolar to micromolar concentrations of Ang II [62, 63]. The effects of Ang II on NHE3, $\mathrm{Na}^{+} / \mathrm{K}^{+}$ATPase, and NBCe1 in PTs are all known to be biphasic [64-67]. Notably, intrarenal concentrations of Ang II are much higher than those in plasma [68]. Accordingly, the inhibitory effect of Ang II on PT transport could have some physiological significance.

Controversial data have been reported as to the receptor subtype(s) responsible for the biphasic effects of Ang II on PT transport [69, 70]. However, Horita and colleagues, by analyzing the NBCel activity in isolated PTs, found that the biphasic effects of Ang II added to bath perfusate were lost in $\mathrm{AT}_{1 \mathrm{~A}}-\mathrm{KO}$ mice [71]. Instead, very high concentrations of Ang II added to bath perfusate induced a slight stimulation of NBCel activity, which was probably mediated by $\mathrm{AT}_{1 \mathrm{~B}}$ $[71,72]$. Zheng and colleagues, by analyzing the bicarbonate absorption rates from isolated PTs, also found that the biphasic effects of Ang II added to luminal perfusate were lost in $\mathrm{AT}_{1 \mathrm{~A}}-\mathrm{KO}$ mice [73]. These results clearly indicate that both luminal and basolateral $\mathrm{AT}_{1 \mathrm{~A}}$ receptors mediate the biphasic effects of Ang II on PT transport.

Regarding the signaling pathways, the activation of PKC and/or the decrease in intracellular cAMP concentrations, which may ultimately result in ERK activation, are thought to mediate the stimulatory effect of Ang II [67, 72, 74]. On the other hand, the activation of phospholipase $\mathrm{A}_{2}$ $\left(\mathrm{PLA}_{2}\right)$ /arachidonic acid/5,6-epoxyeicosatrienoic acid (EET) pathway and/or the NO/cGMP pathway is thought to mediate the inhibitory effect of Ang II [67, 72, 75]. Consistent with this view, Li and colleagues found that the biphasic effects of Ang II were lost and all the concentrations of Ang II induced a similar stimulation of NBCel activity in isolated PTs from cytosolic $\mathrm{PLA}_{2}-\mathrm{KO}$ mice [72].

While the biphasic effects of Ang II on PT transport have been reported in rats, mice, and rabbits $[62,63,65,66,71,73]$, little has been known about the effects of Ang II on human PT transport. To clarify this issue, Shirai and colleagues recently examined the effects of Ang II in isolated human PTs obtained from nephrectomy surgery for renal carcinoma [76]. Surprisingly, they found that Ang II, unlike that in the other species, induced a dose-dependent, profound stimulation of human PT transport via $\mathrm{AT}_{1}$-dependent ERK activation. In wildtype mice, the inhibitory effect of Ang II was dependent on the NO/cGMP/cGMP-dependent kinase II (cGKII) pathway. In cGKII-KO mice, the inhibitory effect of Ang II was lost but 

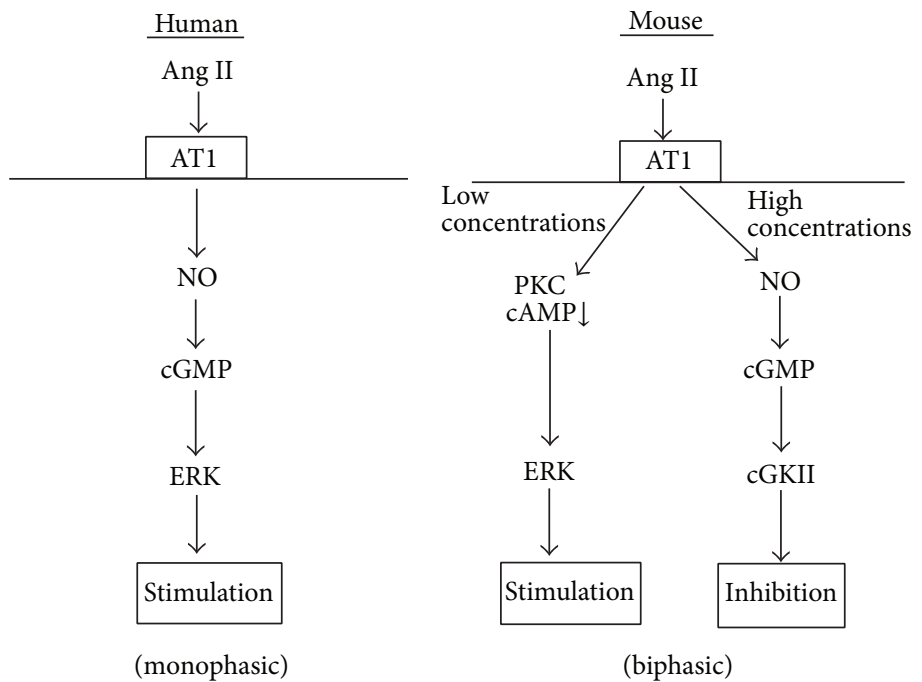

FIGURE 1: Ang II signaling in mouse and human PTs. In mouse PTs, low concentrations of Ang II induce transport stimulation via either PKC activation or decrease in intracellular cAMP resulting in ERK activation, while high concentrations of Ang II induce transport inhibition via $\mathrm{NO} / \mathrm{cGMP} / \mathrm{cGKII}$ pathway. In human PTs, by contrast, Ang II induces dose-dependent transport stimulation via NO/cGMP/ERK pathway.

the NO/cGMP pathway failed to induce the ERK-dependent NBCel activation. By sharp contrast, in human PTs, the NO/cGMP pathway mediated the stimulatory effect of Ang II via cGKII-independent ERK activation. Thus, as shown in Figure 1, the contrasting responses to NO/cGMP pathway seem to be largely responsible for the different modes of PT transport regulation by Ang II in humans and the other species.

At present the molecular mechanisms underlying the species differences in $\mathrm{PT}$ response to NO/cGMP pathway remain unknown. However, previous studies suggest that such species differences may indeed exist. For example, NO is generally thought to work as inhibitory on PT transport in rodents [77, 78]. Furthermore, salt loading into rodents is known to enhance renal NO synthesis, which may facilitate sodium excretion and preservation of normal blood pressure $[79,80]$. In human subjects, however, salt loading fails to induce an adaptive increase in renal NO synthesis [81, 82]. Thus, the role of NO/cGMP in adaptive natriuretic response to salt loading is clearly established in rodents but not in human subjects. Taken together with these considerations, the study by Shirai and colleagues [76] suggests that the unopposed, marked stimulation of PT transport by high intrarenal concentrations of Ang II may play an important role in the pathogenesis of human hypertension. Furthermore, the human-specific stimulatory effect of NO/cGMP pathway on PT transport may represent a novel therapeutic target in hypertension.

\section{Conclusion}

In this paper, we reviewed the physiological and pathophysiological roles of PT transport. Sodium-coupled bicarbonate absorption from PTs plays a critical role in the systemic acid/base balance. Indeed, inactivating mutations in NBCel cause severe pRTA associated with ocular and other extrarenal abnormalities. Sodium transport in PTs may also play an important role in blood pressure regulation. In particular, the stimulatory effect of insulin on PT transport may be involved in the pathogenesis of hypertension associated with metabolic syndrome. Unlike in other species, Ang II dose-dependently stimulates human PT transport via $\mathrm{NO} / \mathrm{cGMP} / \mathrm{ERK}$ pathway, which may represent a novel therapeutic target in human hypertension.

\section{Conflict of Interests}

The authors declare that there is no conflict of interests regarding the publication of this paper.

\section{References}

[1] W. F. Boron, "Acid-base transport by the renal proximal tubule," Journal of the American Society of Nephrology, vol. 17, no. 9, pp. 2368-2382, 2006.

[2] T. Igarashi, J. Inatomi, T. Sekine et al., "Mutations in SLC4A4 cause permanent isolated proximal renal tubular acidosis with ocular abnormalities," Nature Genetics, vol. 23, no. 3, pp. 264266, 1999.

[3] A. Natali, A. Q. Galvan, D. Santoro et al., "Relationship between insulin release, antinatriuresis and hypokalaemia after glucose ingestion in normal and hypertensive man," Clinical Science, vol. 85, no. 3, pp. 327-335, 1993.

[4] A. Quinones-Galvan and E. Ferrannini, "Renal effects of insulin in man," Journal of Nephrology, vol. 10, no. 4, pp. 188-191, 1997.

[5] S. D. Crowley, S. B. Gurley, M. J. Herrera et al., "Angiotensin II causes hypertension and cardiac hypertrophy through its receptors in the kidney," Proceedings of the National Academy of Sciences of the United States of America, vol. 103, no. 47, pp. 17985-17990, 2006. 
[6] S. D. Crowley, S. B. Gurley, M. I. Oliverio et al., "Distinct roles for the kidney and systemic tissues in blood pressure regulation by the renin-angiotensin system," The Journal of Clinical Investigation, vol. 115, no. 4, pp. 1092-1099, 2005.

[7] R. J. Alpern, "Cell mechanisms of proximal tubule acidification," Physiological Reviews, vol. 70, no. 1, pp. 79-114, 1990.

[8] M. Baum, K. Twombley, J. Gattineni et al., "Proximal tubule $\mathrm{Na}^{+} / \mathrm{H}^{+}$exchanger activity in adult $\mathrm{NHE}^{-/-}, \mathrm{NHE}^{-/-}$, and $\mathrm{NHE}^{-/-} / \mathrm{NHE}^{-/-}$mice," American Journal of Physiology: Renal Physiology, vol. 303, no. 11, pp. F1495-F1502, 2012.

[9] W. F. Boron and E. L. Boulpaep, "Intracellular $\mathrm{pH}$ regulation in the renal proximal tubule of the salamander: basolateral $\mathrm{HCO}_{3}{ }^{-}$ transport," The Journal of General Physiology, vol. 81, no. 1, pp. 53-94, 1983.

[10] Y. Kondo and E. Frömter, "Axial heterogeneity of sodiumbicarbonate cotransport in proximal straight tubule of rabbit kidney," Pflügers Archiv, vol. 410, no. 4-5, pp. 481-486, 1987.

[11] K. Yoshitomi, B. C. Burckhardt, and E. Frömter, "Rheogenic sodium-bicarbonate cotransport in the peritubular cell membrane of rat renal proximal tubule," Pflügers Archiv, vol. 405, no. 4, pp. 360-366, 1985.

[12] G. Seki, S. Coppola, and E. Frömter, "The $\mathrm{Na}^{+}-\mathrm{HCO}_{3}{ }^{-}$cotransporter operates with a coupling ratio of $2 \mathrm{HCO}_{3}^{-}$to $1 \mathrm{Na}^{+}$in isolated rabbit renal proximal tubule," Pflügers Archiv, vol. 425, no. 5-6, pp. 409-416, 1993.

[13] S. Müller-Berger, V. V. Nesterov, and E. Frömter, "Partial recovery of in vivo function by improved incubation conditions of isolated renal proximal tubule. II. Change of $\mathrm{Na}-\mathrm{HCO}_{3}$ cotransport stoichiometry and of response to acetazolamide," Pflügers Archiv, vol. 434, no. 4, pp. 383-391, 1997.

[14] S. Müller-Berger, O. Ducoudret, A. Diakov, and E. Frömter, "The renal $\mathrm{Na}-\mathrm{HCO}_{3}$-cotransporter expressed in Xenopus laevis oocytes: change in stoichiometry in response to elevation of cytosolic $\mathrm{Ca}^{2+}$ concentration," Pflügers Archiv, vol. 442, no. 5, pp. 718-728, 2001.

[15] E. Gross, K. Hawkins, N. Abuladze et al., "The stoichiometry of the electrogenic sodium bicarbonate cotransporter $\mathrm{NBC1}$ is cell-type dependent," The Journal of Physiology, vol. 531, no. 3, pp. 597-603, 2001.

[16] M. F. Romero, M. A. Hediger, E. L. Boulpaep, and W. F. Boron, "Expression cloning and characterization of a renal electrogenic $\mathrm{Na}^{+} / \mathrm{HCO}_{3}^{-}$cotransporter," Nature, vol. 387, no. 6631, pp. 409413, 1997.

[17] N. Abuladze, M. Song, A. Pushkin et al., "Structural organization of the human $\mathrm{NBCl}$ gene: $\mathrm{kNBC1}$ is transcribed from an alternative promoter in intron 3," Gene, vol. 251, no. 2, pp. 109122, 2000.

[18] N. Abuladze, I. Lee, D. Newman et al., "Molecular cloning, chromosomal localization, tissue distribution, and functional expression of the human pancreatic sodium bicarbonate cotransporter," The Journal of Biological Chemistry, vol. 273, no. 28, pp. 17689-17695, 1998.

[19] M. F. Romero and W. F. Boron, "Electrogenic $\mathrm{Na}^{+} / \mathrm{HCO}_{3}{ }^{-}$ cotransporters: cloning and physiology," Annual Review of Physiology, vol. 61, pp. 699-723, 1999.

[20] T. Usui, M. Hara, H. Satoh et al., "Molecular basis of ocular abnormalities associated with proximal renal tubular acidosis," The Journal of Clinical Investigation, vol. 108, no. 1, pp. 107-115, 2001.

[21] M. O. Bevensee, B. M. Schmitt, I. Choi, M. F. Romero, and W. F. Boron, "An electrogenic $\mathrm{Na}^{+}-\mathrm{HCO}_{3}{ }^{-}$cotransporter (NBC) with a novel COOH-terminus, cloned from rat brain," American Journal of Physiology: Cell Physiology, vol. 278, no. 6, pp. C1200C1211, 2000.

[22] G. Seki, S. Horita, M. Suzuki et al., "Molecular mechanisms of renal and extrarenal manifestations caused by inactivation of the electrogenic $\mathrm{Na}-\mathrm{HCO}_{3}$ cotransporter NBCel," Frontiers in Physiology, vol. 4, no. 270, pp. 1-8, 2013.

[23] M. Chesler, "Regulation and modulation of $\mathrm{pH}$ in the brain," Physiological Reviews, vol. 83, no. 4, pp. 1183-1221, 2003.

[24] M. Suzuki, W. van Paesschen, I. Stalmans et al., "Defective membrane expression of the $\mathrm{Na}^{+}-\mathrm{HCO}_{3}{ }^{-}$cotransporter $\mathrm{NBCel}$ is associated with familial migraine," Proceedings of the National Academy of Sciences of the United States of America, vol. 107, no. 36, pp. 15963-15968, 2010.

[25] L. R. Gawenis, E. M. Bradford, V. Prasad et al., "Colonic anion secretory defects and metabolic acidosis in mice lacking the $\mathrm{NBCl} \mathrm{Na}{ }^{+} / \mathrm{HCO}_{3}{ }^{-}$cotransporter," The Journal of Biological Chemistry, vol. 282, no. 12, pp. 9042-9052, 2007.

[26] Y.-F. Lo, S.-S. Yang, G. Seki et al., "Severe metabolic acidosis causes early lethality in NBC1 W516X knock-in mice as a model of human isolated proximal renal tubular acidosis," Kidney International, vol. 79, no. 7, pp. 730-741, 2011.

[27] P. J. Schultheis, L. L. Clarke, P. Meneton et al., "Renal and intestinal absorptive defects in mice lacking the NHE3 $\mathrm{Na}^{+} / \mathrm{H}^{+}$ exchanger," Nature Genetics, vol. 19, no. 3, pp. 282-285, 1998.

[28] J. Levesque and B. Lamarche, "The metabolic syndrome: definitions, prevalence and management," Journal of Nutrigenetics and Nutrigenomics, vol. 1, no. 3, pp. 100-108, 2008.

[29] F. A. El-Atat, S. N. Stas, S. I. Mcfarlane, and J. R. Sowers, "The relationship between hyperinsulinemia, hypertension and progressive renal disease," Journal of the American Society of Nephrology, vol. 15, no. 11, pp. 2816-2827, 2004.

[30] J. E. Hall, D. A. Hildebrandt, and J. Kuo, "Obesity hypertension: role of leptin and sympathetic nervous system," American Journal of Hypertension, vol. 14, no. 6, part 2, pp. 103S-115S, 2001.

[31] E. Sohara, T. Rai, S.-S. Yang et al., "Acute insulin stimulation induces phosphorylation of the $\mathrm{Na}-\mathrm{Cl}$ cotransporter in cultured distal mpkDCT cells and mouse kidney," PLoS ONE, vol. 6, no. 8, article e24277, 2011.

[32] B. L. Blazer-Yost, M. A. Esterman, and C. J. Vlahos, "Insulinstimulated trafficking of $\mathrm{ENaC}$ in renal cells requires $\mathrm{PI}$ 3-kinase activity," American Journal of Physiology: Cell Physiology, vol. 284, no. 6, pp. C1645-C1653, 2003.

[33] Y. Marunaka, N. Hagiwara, and H. Tohda, "Insulin activates single amiloride-blockable $\mathrm{Na}$ channels in a distal nephron cell line (A6)," American Journal of Physiology: Renal Fluid and Electrolyte Physiology, vol. 263, no. 3, part 2, pp. F392-F400, 1992.

[34] S. Tiwari, S. Riazi, and C. A. Ecelbarger, "Insulin's impact on renal sodium transport and blood pressure in health, obesity, and diabetes," American Journal of Physiology: Renal Physiology, vol. 293, no. 4, pp. F974-F984, 2007.

[35] G. Frindt and L. G. Palmer, "Effects of insulin on Na and K transporters in the rat CCD," American Journal of Physiology: Renal Physiology, vol. 302, no. 10, pp. F1227-F1233, 2012.

[36] M. Baum, "Insulin stimulates volume absorption in the rabbit proximal convoluted tubule," The Journal of Clinical Investigation, vol. 79, no. 4, pp. 1104-1109, 1987.

[37] E. Feraille, M. L. Carranza, M. Rousselot, and H. Favre, "Insulin enhances sodium sensitivity of Na-K-ATPase in isolated rat proximal convoluted tubule," American Journal of Physiology: 
Renal Fluid and Electrolyte Physiology, vol. 267, no. 1, part 2, pp. F55-F62, 1994.

[38] F. A. Gesek and A. C. Schoolwerth, "Insulin increases $\mathrm{Na}^{+}-\mathrm{H}^{+}$ exchange activity in proximal tubules from normotensive and hypertensive rats," American Journal of Physiology: Renal Fluid and Electrolyte Physiology, vol. 260, no. 5, part 2, pp. F695-F703, 1991.

[39] O. S. Ruiz, Y.-Y. Qiu, L. R. Cardoso, and J. A. Arruda, "Regulation of the renal $\mathrm{Na}-\mathrm{HCO}_{3}$ cotransporter: IX. Modulation by insulin, epidermal growth factor and carbachol," Regulatory Peptides, vol. 77, no. 1-3, pp. 155-161, 1998.

[40] J. E. Hall, "Hyperinsulinemia: a link between obesity and hypertension?" Kidney International, vol. 43, no. 6, pp. 14021417, 1993.

[41] J.-A. Kim, M. Montagnani, K. K. Kwang, and M. J. Quon, "Reciprocal relationships between insulin resistance and endothelial dysfunction: molecular and pathophysiological mechanisms," Circulation, vol. 113, no. 15, pp. 1888-1904, 2006.

[42] H. O. Steinberg, H. Chaker, R. Leaming, A. Johnson, G. Brechtel, and A. D. Baron, "Obesity/insulin resistance is associated with endothelial dysfunction. Implications for the syndrome of insulin resistance," The Journal of Clinical Investigation, vol. 97, no. 11, pp. 2601-2610, 1996.

[43] M. Benito, "Tissue-specificity of insulin action and resistance," Archives of Physiology and Biochemistry, vol. 117, no. 3, pp. 96104, 2011.

[44] S. B. Biddinger and C. R. Kahn, "From mice to men: insights into the insulin resistance syndromes," Annual Review of Physiology, vol. 68 , pp. 123-158, 2006.

[45] A. Nandi, Y. Kitamura, C. R. Kahn, and D. Accili, "Mouse models of insulin resistance," Physiological Reviews, vol. 84, no. 2, pp. 623-647, 2004.

[46] C. M. Rondinone, L.-M. Wang, P. Lonnroth, C. Wesslau, J. H. Pierce, and U. Smith, "Insulin receptor substrate (IRS) 1 is reduced and IRS-2 is the main docking protein for phosphatidylinositol 3-kinase in adipocytes from subjects with non-insulin-dependent diabetes mellitus," Proceedings of the National Academy of Sciences of the United States of America, vol. 94, no. 8, pp. 4171-4175, 1997.

[47] I. Shimomura, M. Matsuda, R. E. Hammer, Y. Bashmakov, M. S. Brown, and J. L. Goldstein, "Decreased IRS-2 and increased SREBP-1c lead to mixed insulin resistance and sensitivity in livers of lipodystrophic and ob/ob mice," Molecular Cell, vol. 6, no. 1, pp. 77-86, 2000.

[48] Y. Zheng, H. Yamada, K. Sakamoto et al., "Roles of insulin receptor substrates in insulin-induced stimulation of renal proximal bicarbonate absorption," Journal of the American Society of Nephrology, vol. 16, no. 8, pp. 2288-2295, 2005.

[49] C. Catena, A. Cavarape, M. Novello, G. Giacchetti, and L. A. Sechi, "Insulin receptors and renal sodium handling in hypertensive fructose-fed rats," Kidney International, vol. 64, no. 6, pp. 2163-2171, 2003.

[50] P. Skott, A. Vaag, N. E. Bruun et al., "Effect of insulin on renal sodium handlings in hyperinsulinaemic type 2 (non-insulindependent) diabetic patients with peripheral insulin resistance," Diabetologia, vol. 34, no. 4, pp. 275-281, 1991.

[51] P. Strazzullo, G. Barba, F. P. Cappuccio et al., "Altered renal sodium handling in men with abdominal adiposity: a link to hypertension," Journal of Hypertension, vol. 19, no. 12, pp. 21572164, 2001.

[52] P. Strazzullo, A. Barbato, F. Galletti et al., "Abnormalities of renal sodium handling in the metabolic syndrome. Results of the Olivetti Heart Study," Journal of Hypertension, vol. 24, no. 8, pp. 1633-1639, 2006.

[53] A. Mima, Y. Ohshiro, M. Kitada et al., "Glomerular-specific protein kinase C-B-induced insulin receptor substrate-1 dysfunction and insulin resistance in rat models of diabetes and obesity," Kidney International, vol. 79, no. 8, pp. 883-896, 2011.

[54] J. Zhang, J. Ou, Y. Bashmakov, J. D. Horton, M. S. Brown, and J. L. Goldstein, "Insulin inhibits transcription of IRS-2 gene in rat liver through an insulin response element (IRE) that resembles IREs of other insulin-repressed genes," Proceedings of the National Academy of Sciences of the United States of America, vol. 98, no. 7, pp. 3756-3761, 2001.

[55] G. I. Welsh, L. J. Hale, V. Eremina et al., "Insulin signaling to the glomerular podocyte is critical for normal kidney function," Cell Metabolism, vol. 12, no. 4, pp. 329-340, 2010.

[56] T. Kanjanabuch, L.-J. Ma, J. Chen et al., "PPAR- $\gamma$ agonist protects podocytes from injury," Kidney International, vol. 71, no. 12, pp. 1232-1239, 2007.

[57] Y. Endo, M. Suzuki, H. Yamada et al., "Thiazolidinediones enhance sodium-coupled bicarbonate absorption from renal proximal tubules via PPAR $\gamma$-dependent nongenomic signaling," Cell Metabolism, vol. 13, no. 5, pp. 550-561, 2011.

[58] V. Vallon, E. Hummler, T. Rieg et al., "Thiazolidinedioneinduced fluid retention is independent of collecting duct $\alpha \mathrm{ENaC}$ activity," Journal of the American Society of Nephrology, vol. 20, no. 4, pp. 721-729, 2009.

[59] T. Inagami, D. F. Guo, and Y. Kitami, "Molecular biology of angiotensin II receptors: an overview," Journal of Hypertension. Supplement, vol. 12, no. 10, pp. S83-S94, 1994.

[60] T. Ichiki, P. A. Labosky, C. Shiota et al., "Effects on blood pressure exploratory behaviour of mice lacking angiotensin II type-2 receptor," Nature, vol. 377, no. 6551, pp. 748-750, 1995.

[61] S. B. Gurley, A. D. Riquier-Brison, J. Schnermann et al., " $A T_{1 A}$ angiotensin receptors in the renal proximal tubule regulate blood pressure," Cell Metabolism, vol. 13, no. 4, pp. 469-475, 2011.

[62] P. J. Harris and J. A. Young, "Dose dependent stimulation and inhibition of proximal tubular sodium reabsorption by angiotensin II in the rat kidney," Pflügers Archiv, vol. 367, no. 3, pp. 295-297, 1977.

[63] V. L. Schuster, J. P. Kokko, and H. R. Jacobson, “Angiotensin II directly stimulates sodium transport in rabbit proximal convoluted tubules," The Journal of Clinical Investigation, vol. 73, no. 2, pp. 507-515, 1984.

[64] A. A. Banday and M. F. Lokhandwala, "Loss of biphasic effect on $\mathrm{Na} / \mathrm{K}$-ATPase activity by angiotensin II involves defective angiotensin type 1 receptor-nitric oxide signaling," Hypertension, vol. 52, no. 6, pp. 1099-1105, 2008.

[65] S. Coppola and E. Frömter, "An electrophysiological study of angiotensin II regulation of $\mathrm{Na}-\mathrm{HCO}_{3}$ cotransport and $\mathrm{K}$ conductance in renal proximal tubules. I. Effect of picomolar concentrations," Pflügers Archiv, vol. 427, no. 1-2, pp. 143-150, 1994.

[66] S. Coppola and E. Frömter, "An electrophysiological study of angiotensin II regulation of $\mathrm{Na}-\mathrm{HCO}_{3}$ cotransport and $\mathrm{K}$ conductance in renal proximal tubules. II. Effect of micromolar concentrations," Pflügers Archiv, vol. 427, no. 1-2, pp. 151-156, 1994.

[67] P. Houillier, R. Chambrey, J. M. Achard, M. Froissart, J. Poggioli, and M. Paillard, "Signaling pathways in the biphasic effect of angiotensin II on apical $\mathrm{Na} / \mathrm{H}$ antiport activity in proximal tubule," Kidney International, vol. 50, no. 5, pp. 1496-1505, 1996. 
[68] L. G. Navar, L. M. Harrison-Bernard, C.-T. Wang, L. Cervenka, and K. D. Mitchell, "Concentrations and actions of intraluminal angiotensin II," Journal of the American Society of Nephrology, vol. 10, supplement 11, pp. S189-S195, 1999.

[69] D. Haithcock, H. Jiao, X.-L. Cui, U. Hopper, and J. G. Douglas, "Renal proximal tubular AT2 receptor: signaling and transport," Journal of the American Society of Nephrology, vol. 10, supplement 11, pp. S69-S74, 1999.

[70] J. Poggioli, G. Lazar, P. Houillier, J. P. Gardin, J. M. Achard, and M. Paillard, "Effects of angiotensin II and nonpeptide receptor antagonists on transduction pathways in rat proximal tubule," American Journal of Physiology: Cell Physiology, vol. 263, no. 4, part 1, pp. C750-C758, 1992.

[71] S. Horita, Y. Zheng, C. Hara et al., "Biphasic regulation of $\mathrm{Na}^{+}-\mathrm{HCO}_{3}{ }^{-}$cotransporter by angiotensin II type $1 \mathrm{~A}$ receptor," Hypertension, vol. 40, no. 5, pp. 707-712, 2002.

[72] Y. Li, H. Yamada, Y. Kita et al., "Roles of ERK and cPLA2 in the angiotensin II-mediated biphasic regulation of $\mathrm{Na}^{+}-\mathrm{HCO}_{3}{ }^{-}$ transport," Journal of the American Society of Nephrology, vol. 19, no. 2, pp. 252-259, 2008.

[73] Y. Zheng, S. Horita, C. Hara et al., "Biphasic regulation of renal proximal bicarbonate absorption by luminal $\mathrm{AT}_{1 \mathrm{~A}}$ receptor," Journal of the American Society of Nephrology, vol. 14, no. 5, pp. 1116-1122, 2003.

[74] F.-Y. Liu and M. G. Cogan, "Angiotensin II stimulates early proximal bicarbonate absorption in the rat by decreasing cyclic adenosine monophosphate," The Journal of Clinical Investigation, vol. 84, no. 1, pp. 83-91, 1989.

[75] C. Zhang and P. R. Mayeux, "NO/cGMP signaling modulates regulation of $\mathrm{Na}^{+}-\mathrm{K}^{+}$-ATPase activity by angiotensin II in rat proximal tubules," American Journal of Physiology: Renal Physiology, vol. 280, no. 3, pp. F474-F479, 2001.

[76] A. Shirai, O. Yamazaki, S. Horita et al., "Angiotensin II dosedependently stimulates human renal proximal tubule transport by the nitric oxide/guanosine $3^{\prime}, 5^{\prime}$-cyclic monophosphate pathway," Journal of the American Society of Nephrology, 2014.

[77] M. Liang and F. G. Knox, "Production and functional roles of nitric oxide in the proximal tubule," American Journal of Physiology: Regulatory Integrative and Comparative Physiology, vol. 278, no. 5, pp. R1117-R1124, 2000.

[78] P. A. Ortiz and J. L. Garvin, "Cardiovascular and renal control in NOS-deficient mouse models," American Journal of Physiology: Regulatory Integrative and Comparative Physiology, vol. 284, no. 3, pp. R628-R638, 2003.

[79] P. J. Shultz and J. P. Tolins, "Adaptation to increased dietary salt intake in the rat. Role of endogenous nitric oxide," The Journal of Clinical Investigation, vol. 91, no. 2, pp. 642-650, 1993.

[80] J. P. Tolins and P. J. Shultz, "Endogenous nitric oxide synthesis determines sensitivity to the pressor effect of salt," Kidney International, vol. 46, no. 1, pp. 230-236, 1994.

[81] F. S. Facchini, C. DoNascimento, G. M. Reaven, J. W. Yip, X. P. Ni, and M. H. Humphreys, "Blood pressure, sodium intake, insulin resistance, and urinary nitrate excretion," Hypertension, vol. 33, no. 4, pp. 1008-1012, 1999.

[82] R. J. Schmidt, W. H. Beierwaltes, and C. Baylis, "Effects of aging and alterations in dietary sodium intake on total nitric oxide production," American Journal of Kidney Diseases, vol. 37, no. 5, pp. 900-908, 2001. 

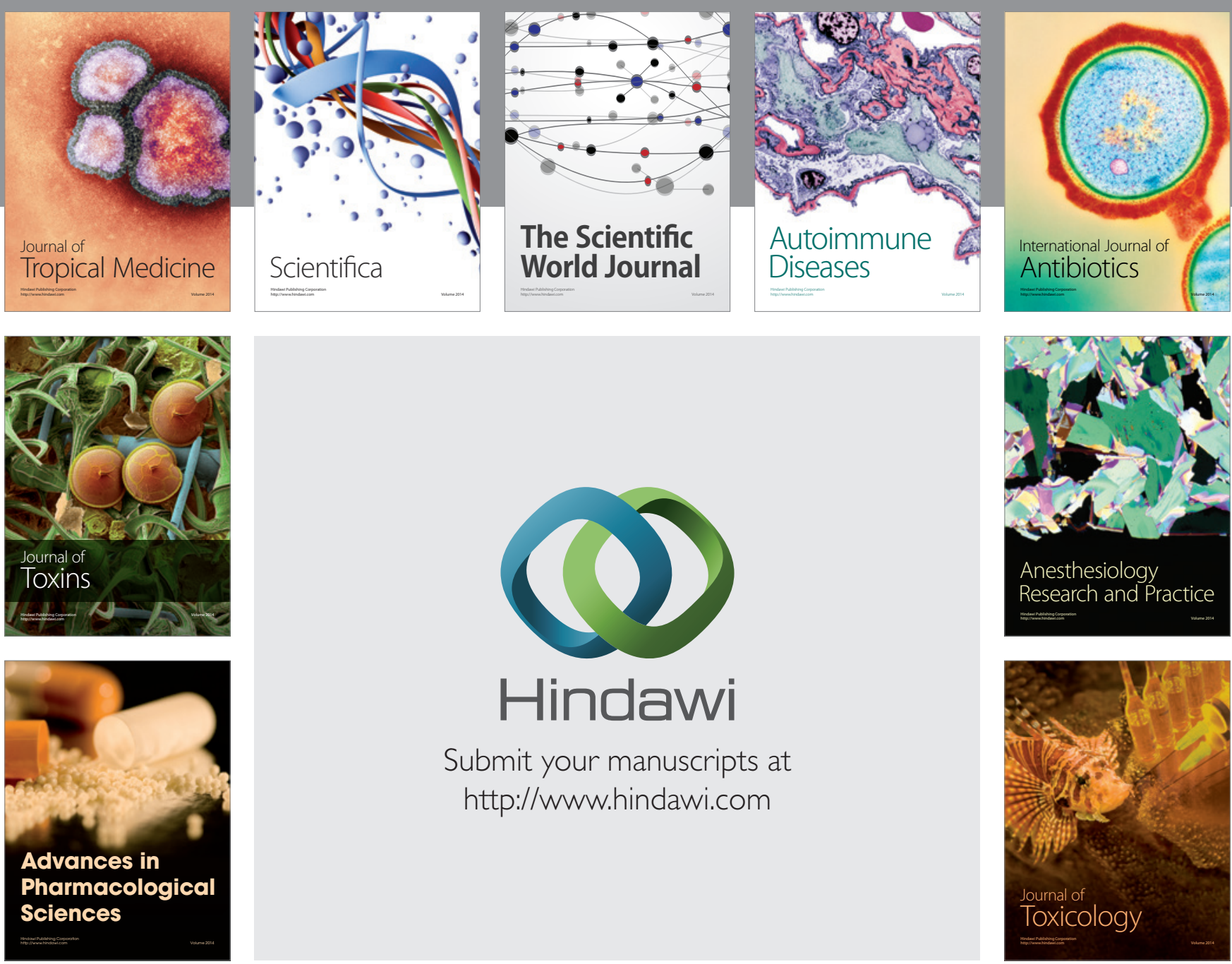

\section{Hindawi}

Submit your manuscripts at

http://www.hindawi.com
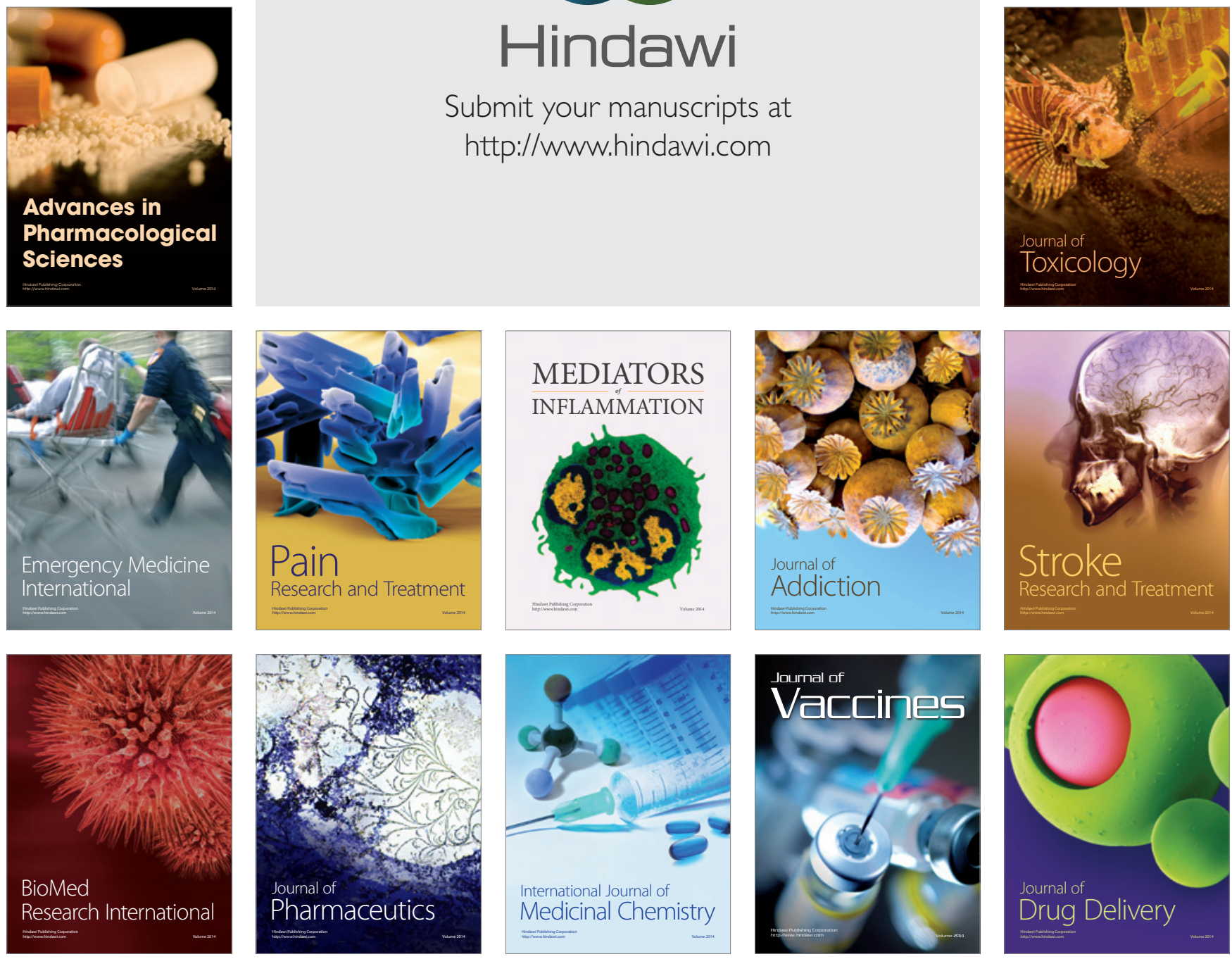